\title{
Kimlik Arayışında Yeni Bir Eğilim: Orta Asya'da Atayurt Turizmi
}

\author{
Kemal KANTARCI ${ }^{1}$, Paşa Mustafa ÖZYURT ${ }^{2}$ ve Murat Alper BAŞARAN ${ }^{3}$
}

\section{$\ddot{O} z$}

Orhon yazıtlarından biri olan Bilge Kağan yazıtında "Türk halkı (bu huyundan) vazgeç ve nadim ol! Kutsal Ötüken Dağları Halkı, (sen kendin yerini yurdunu bırakıp) gittin" ifadesi yer almaktadır. Bilge Kağan tarafindan Ötüken ormanında kal, oradan ayrllma anlamında kullanılan bu ifade bir anlamda bütün dünyadaki ve özellikle Türkiye'deki Türklerin ata yurtlarını ziyaret etme ve kökleri ile ilgili mirası görme amacıyla yapacakları seyahatlerin temel motivasyonu ve sloganı olabilir. Günümüzde bireylerin, atalarını ve köklerini araştırma, kimliğini bulma, güçlendirme ve geçmiş zamanı yaşama isteği önemli bir turizm alanı haline gelmiştir. Bu çalışmanın öncelikli amacını miras ve nostalji odaklı ortaya çıkan bu yeni turizm faaliyetleriyle ilgili uluslararası alanyazında kullanılan kavramların Türkçe karşıılıklarının geliştirilmesidir. Ayrıca, bu kapsamda Türkiye ile Orta Asya arasında ortak kültürel mirasa dayalı olarak geliştirilebilecek turizm arz ve talep koşullarının planlanmasına katkı sunulması çalışmanın bir diğer amacını oluşturmaktadır. Alanyazına ve ikincil verilere dayalı olarak yapılan bu çalışma, miras odaklı gelişen turizm türlerinin Türkler ve Türkiye ve Orta Asya Ülkeleri için önemli bir firsat olduğunu ortaya koymaktadır.

Anabtar Kelimeler: Atasoy Turizmi, Atayurt Turizmi, Soy İzi Turizmi, Orta Asya, Türk Dünyas1

\section{A New Inclination in Searching for the Identity: Root Tourism in Central Asia}

\begin{abstract}
It is said in Bilge Kaghan inscription, one of the Orkhon inscriptions, that "Turkish people give up this habit and regret it! People of the holy Otuken Mountain, you left your fatherland”. This expression used by Bilge Kaghan to remark the importance of staying in Otuken Forest and not leaving there, in a sense, can be as a principal motivator and slogan of the travels for the Turks worldwide in order to visit their homelands to learn about the roots and heritage. Nowadays, the urge for searching the ancestor and the roots, finding and reinforcing the identity and experiencing the old times is an important tourism field. The primary aim of this study is to conceptualize the new notions used in the international literature that arise from new tourism activities such as nostalgia and root tourism in the Turkish language. Besides, contributing to the planning process of the supply and demand conditions that might be developed between Turkey and Central Asia based on the common cultural heritage is another important aim of the study. The research, based on the literature review and secondary data, reveal that root tourism is a significant opportunity for the Turks and Turkey and Central Asia.
\end{abstract}

Key Words: Ancestral Tourism, Root Tourism, Genealogy Tourism, Central Asia, Turkish World

\section{Atıf İçin / Please Cite As:}

Kantarc1, K., Özyurt, P. M. ve Başaran, M. A. (2021). Kimlik arayışında yeni bir eğilim: Orta Asya'da Atayurt turizmi. Manas Sosyal Araştrmalar Dergisi, 10(ÖS), 113-124.

Geliş Tarihi / Received Date: 16.08.2021

Kabul Tarihi / Accepted Date: 19.12.2021

\footnotetext{
1 Prof. Dr. - Alanya Alaaddin Keykubat Üniversitesi Turizm Fakültesi, kantarci07@gmail.com

(D) ORCID: 0000-0002-9572-2959

2 Dr. Öğr. Üyesi - Giresun Üniversitesi Turizm Fakültesi, pasa.mustafa@giresun.edu.tr

(D) ORCID: 0000-0003-2968-7988

3 Prof. Dr. - Alanya Alaaddin Keykubat Üniversitesi Mühendislik Fakültesi, muratalper@yahoo.com 


\section{Giriş}

Çağımızın en önemli olguları arasında yer alan turizm, coğrafi olarak yer değiştirme sürecini kapsamaktadır. Bununla beraber insanların nereye, ne zaman, nasıl ve hangi maliyetlere katlanarak seyahat edeceğine çeşitli faktörler etki etmektedir. Günümüzde ulusal ve uluslararası düzeyde gerçekleşen turizm hareketliliğinin en önemli motivasyon kaynaklarından biri "miras" olarak belirtilmektedir. Miras turizmi, zamanın çeşitli boyutlarını deneyimleme amacıyla yapılan ve içerisinde romantizm ve nostalji de barındıran seyahatleri ifade etmektedir (Park, 2010, s. 117). Geleneksel olarak kültür turizmi destinasyonları ve çekicilikleri etrafinda gelişen miras turizminin son dönemlerde daha bireysel gerekçeler nedeniyle gelişen alt alanları ortaya çıkmıstır. Bu bakımdan, bireysel mirası arama veya ait olunan kültürü yakından tanıma amacıyla yapılan seyahatler yaygınlık kazanmaktadır. Pek çok insan kendi kimlik ve aidiyet duygusunu güçlendirmek amacıyla atalarının yaşadığı yerleri ziyaret etmekte, yakın ve uzak akrabalarla iletişim kurmakta ve aile geçmişiyle ilgili bilgi ve belge toplamaktadır (Timothy ve Schmidt, 2011, s. 180; Timothy ve Teye, 2004, s. 111).

Tarih boyunca dünyanın her yerinde çeşitli nedenlerle yaşanan bireysel ve kitlesel göç hareketleri, bu turizm türünün gelişmesini teşvik eden en önemli etmenlerden biri olarak belirtilmektedir (Murdy, Alexander ve Bryce, 2018, s. 14). Yapılan göçler sonucunda uluslar ve bireyler ait oldukları kültürü ve coğrafyaları bırakarak yaşamlarına farklı yerlerde devam etmiştir. Bunlara ek olarak, daha iyi yaşam koşullarına ulaşma amacıyla yapılan göçlerin, yirmi birinci yüzyılda da bireysel ve kitlesel düzeyde devam ettiği görülmektedir. Yüzylllar içerisinde yaşanan bu göç hareketleri günümüzde pek çok ülkenin demografik yapısına da yansımaktadır. Göçmenler ülkesi olarak tanımlanan Amerika Birleşik Devletleri'nin yaklaşık 330 milyon olan nüfusunun, 43,9 milyonu Afrika kökenli, 41,2 milyonu Alman kökenli, 30,1 milyonu İrlanda kökenli, 25,2 milyonu İngiliz kökenli, 16,4 milyonu İtalyan kökenli ve 8,8 milyonunun ise Polonya kökenlilerden oluşmaktadır (United States Census Bureau, 2018). Güney Amerika ülkelerinin pek çoğunda ve Avustralya'da önemli oranda Avrupa kökenli nüfus yer alırken, Yakın Çağdaki köle ticareti nedeniyle pek çok Avrupa ülkesinde ise önemli oranda Afrika kökenli nüfus yer almaktadır. Geçmişte atalarının çeşitli nedenlerle terk etmek zorunda kaldıkları coğrafyalar, günümüzde bireylerin geçmişle bağ kurma amacıyla yaptıkları seyahatlerin varış noktası haline gelmiştir. Dünya tarihinde önemli bir yer tutan Türk ulusu ise tarih boyunca sürekli göç etmiş ve farklı coğrafyalarda medeniyetler kurmuştur. $\mathrm{Bu}$ medeniyetler, Tanr1 Dağları eteklerinden Orta Asya'ya, İran'dan Hindistan'a, Kuzey Afrika'dan Balkanlar'a kadar oldukça geniş bir alana yayılmıştır. Günümüzde dünya genelinde Türklerin sayısının yaklaşı 250 milyon civarında olduğu ve böylece Türklerin Çinliler, Hintliler ve Endonezyalılardan sonra dünyanın en kalabalık dördüncü milleti olduğu belirtilmektedir (Türk Dünyası Parlamenterler Birliği, 2021). Bu bakımdan Türk ulusunun ortak geçmiş ve kültür bağı yoluyla aidiyet geliştirebileceği coğrafyaların oldukça geniş olduğu ifade edilebilir.

Günümüzde dünyayı siyasi sınırlara ayıran haritaların yanı sıra, bireylerin ve ulusların geçmişte göç yoluyla ayrıldıkları fakat aile bağı veya ortak kültür nedeniyle aidiyet duyup kimlik tanımlamasını yaptıkları kültür coğrafyası haritalarının önemi miras turizmi ve alt alanlarının gelişmesini teşvik etmektedir. Buradan hareketle, bu çalışmada miras turizmi kapsamında gelişen "Atasoy turizmi”" (Ancestral Tourism), "Atayurt turizmi" (Root Tourism) ve Soy İzi turizmi (Geneaology Tourism) kavramları ele alınmaktadır. Çalışma özellikle, ata mirası ve kültür coğrafyası ziyaretlerini kapsayan "Atayurt turizmine" odaklanmaktadır. Bununla beraber çalşşa kapsamında Türk tarihinin en önemli coğrafyalarından biri olan Orta Asya bölgesine yönelik "atayurt" motivasyonlu turizm hareketliliği Türkiye pazarı üzerinden incelenmekte ve bölgede atayurt turizm pazarının ve olanaklarının geliştirilebilmesi için öneriler sunulmaktadır. Böylece çalışma, miras ve atayurt turizm alanları ile ilgili bölgedeki politika belirleyici ve uygulayıcıların konuya odaklanmalarını sağlamayı amaçlamaktadır.

$\mathrm{Bu}$ araştırmanın alanyazına iki yönden önemli katkılar sağlayacağı öngörülmektedir. Bunlardan birincisi, yabancı alanyazında özellikle son yirmi yıldır incelenen (McCain ve Ray, 2003; Santos ve Yan, 2010; Timothy, 1997) fakat henüz genel kabul görmüş Türkçe kavram karşılıkları geliştirilmemiş olan miras ve soy bilimsel odaklı ortaya çıan turizm kavramlarının Türkçeleştirilip alanyazına kazandırılmasıdır. Kavramların milli dile çevrilmesi ve kullanımının yaygınlaştırılması alanın daha kolay ve derinlikli bir şekilde anlaşılması konusunda hayati öneme sahiptir. Ayrıca, son üç yüzyılda kimlik, milliyetçilik, aidiyet, miras, kültür ve etnik yapı kavramları anlam ve önemini arttırarak geniş kitleleri etkisi altına almıştır. Bu bakımdan, ifade edilen bu kavramları kapsayan miras turizmi alt alanlarının Türkçeleştirilmesi önemli 
görülmektedir. Türkçeleştirilen bu kavramların kullanım yaygınlı̆̆ının zamanla yerleşeceği öngörülmektedir.

Çalışmanın bir diğer önemli katkısı ise miras motivasyonlu ortaya çıkan ve Türkçeleştirilen bu turizm türlerinin, Türkiye ile Orta Asya coğrafyası arasındaki turizm hareketliliğinin geliştirilmesinde kullanım olanaklarını incelemesidir. Orta Asya ülkelerinin turizm verileri incelendiğinde, sahip oldukları potansiyelden yeterince yararlanamadıkları görülmektedir (Dünya Turizm Örgütü, 2020). Zengin ve özgün kaynaklarına rağmen, Orta Asya ülkeleri turizm altyapısı, ürün geliştirme ve talep yaratma gibi rekabet gücünü belirleyen alanlarda gelişmeye ihtiyaç duymaktadır. Bu çalş̧manın konusu olan atayurt turizm ürünü ve deneyimi Orta Asya ve diğer ilgili coğrafyalar açısından Türk dünyası için ortak mirasa dayalı özgün bir alandır. Bölge için yeni olan bu turizm ürün ve kavramlarının, Orta Asya Ülkelerinin turizmde sürdürülebilir rekabet edebilme yeteneklerinin geliştirilmesine yönelik planlanması üzerinde durulmaktadır. $\mathrm{Bu}$ amaçla çalışmanın, bölgedeki turizm sektörünün rekabetçi stratejiler ve ürünler geliştirmesi konusuna yardımcı olacağı öngörülmektedir.

Çalışmanın ilk bölümünde miras motivasyonlu ortaya çıkan turizm türleri kavramsal olarak incelenmiş ve bu turizm türlerinin Türkçe kavram karşılıkları geliştirilmiştir. İkinci bölümde ise, bu turizm türleri Türkiye-Orta Asya ekseninde değerlendirilmiştir. Bu aşamada Türkiye ile bölge arasındaki ziyaretçi hareketliliği ikincil veriler üzerinden incelenmiş ve atayurt turizmi kapsamında arz ve talep koşulları, pazar potansiyeli, ziyaretçi profili, ürün ve hizmet yapısı gibi hareketliliği arttırmaya yönelik stratejiler üzerinde durulmuştur. Çalışmanın son bölümünde ise, politika yapıcılara ve destinasyon örgütlerine yönelik önerilere yer verilmiştir.

\begin{tabular}{|c|}
\hline Imas1 \\
\hline $\begin{array}{l}\text { Turizm ve miras arasındaki çok boyutlu ilişkiler, gelenek ve modernite arasındaki etkileşimden ortaya } \\
\text { maktadır. Sanayi devrimini takiben on dokuzuncu yüzyl geçmişin yıkımı ve yenisiyle yer değiştirmesi } \\
\text { cak tasvir edilirken, yirminci yüzyıl ise geçmişle iletşsim kurmak için yeni yollar bulmaya çalışlan bir } \\
\text { snndalıkla tasvir edilmektedir. Bu değişim, geleneksel değerlere dönüş yoluyla yenilik arayan küresel } \\
\text { ginler arasındaki son eğilimlere ve turizm pazarına sunulan ürünlere de yansımaktadır (Nuryanti, 1996, } \\
\text { 50). }\end{array}$ \\
\hline $\begin{array}{l}\text { İnsanlığın kendi köklerini bilmek istemesi doğal bir arzudur. Bununla birlikte, sadece bir ailenin } \\
\text { leri arasındaki bağlantılar değil, aynı zamanda ait oldukları yer ve kültürle olan ilişkileri de önemlidir. } \\
\text { as motivasyonlu gelişen turizm çeşitleri geçmiş, şimdiki zaman ve gelecek arasında daha güçlü } \\
\text { lantılar kurma potansiyeline sahiptir. Zamanın farkl boyutlarını deneyimleme imkânı sunan miras } \\
\text { zmi, insanların hem çevreyi algılamalarına hem de kendi kimlik ve keşif süreçlerine katkı sunmaktadır } \\
\text { Iryanti, 1996, s. 250; Park, 2010, s. 117). }\end{array}$ \\
\hline $\begin{array}{l}\text { Oldukça geniş bir kapsamda değerlendirilen miras turizminin zaman içerisinde ortaya çıkan alt } \\
\text { erinden biri "Atasoy" turizmidir. Geçmişle bağ kurmak veya var olan bağları güçlendirmek amacıyla } \\
\text { lan seyahatleri kapsayan atasoy turizmi (Alexander, Bryce ve Murdy, 2017, s. 546) etnik ve kültürel } \\
\text { ları içermektedir (Park, 2010, s. 117). Bu turizm faaliyeti temelde kimlik ve aidiyet unsuru etrafinda } \\
\text { mmekte ve geçmişe yönelik bir nostalji duygusu barındırmaktadır (Tan ve Bakar, 2018, s. 22). Turizm } \\
\text { yetlerinde genel olarak ziyaretçilerin evden uzaklaşması süreci yaşanırken, atasoy turizminde ise } \\
\text { ysel veya kültürel yakınlık, ortak geçmiş ve benzerlik nedeniyle bir anlamda "eve dönüş süreci" } \\
\text { nmaktadır (Bhandari. 2016, s. 914). }\end{array}$ \\
\hline
\end{tabular}




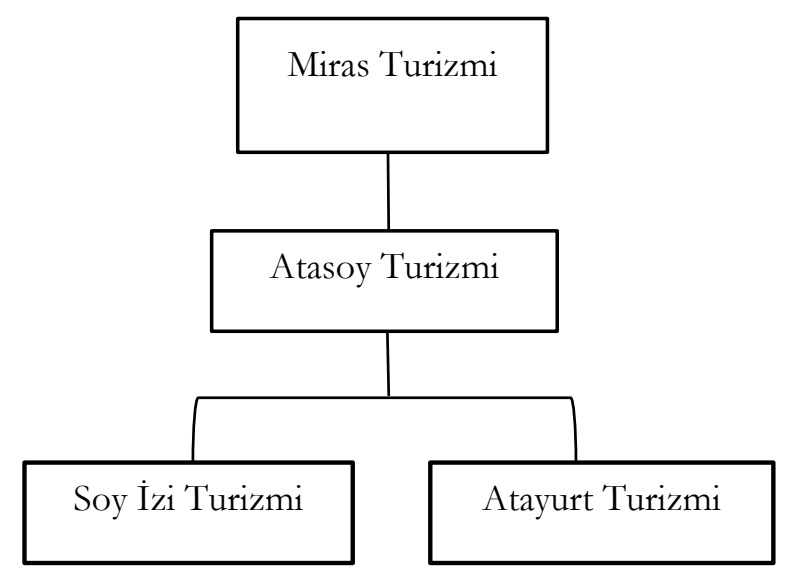

Şekil 1. Miras Turizmi Kapsamında Atasoy Turizmi ve Alt Türlerinin Gösterimi

Yakın veya uzak geçmişin mirasını deneyimleme ve duygusal ve somut bağ kurma ile ilgili olan Atasoy turizmi (Park, 2010, s. 117), motivasyon kaynağına göre iki alt alana ayrllmaktadır. Bunlardan ilki, aile soy ağacını ortaya çıkarma ve soy geçmişini öğrenme gibi daha bireysel gerekçelerle gelişen "Soy İzi Turizmi", ikincisi ise daha çok kültürel aidiyet ve kimlik odaklı gelişen ve kültür coğrafyası seyahatlerini içeren “Atayurt Turizmi”dir (Alexander vd., 2017, s. 546; Higginbotham, 2012, s. 19).

Soy izi tanım olarak doğumlar, evlilikler ve ölümler hakkında temel bilgilerin bir aile soy ağac1 oluşturmak için birbirine bağlandığı süreci ifade etmektedir. Bu bakımdan bireysel bir keşif ve yolculuğu kapsamaktadır. Soy izi turizmi ise aile geçmişini ortaya çıarma, izleme ve ilgili mekânları ziyaret etme süreçlerini kapsayan ve hem mekânsal hem de duygusal olarak geçmişe geri dönme amacı taşıyan turizm çeşidi olarak ifade edilmektedir (Birtwistle, 2005, s. 59-68; Higginbotham, 2012, s. 190). Takip edilebilen geçmiş çerçevesinde gelişen soy izi turizmi, aynı zamanda aile ağacından ulaşılan kişilerin etnik kökenleri, dini inançları, yaşam tarzları, meslekleri, değerleri, kişilikleri, nerede ve nasıl yaşadıkları gibi bilgilere de ulaşmayı da amaçlamaktadır (Birtwistle, 2005, s. 60). Soy izi turizmi, geçmişe doğru aile ağacını oluşturmayı amaçlarken, bir yandan ise yaşayan akrabalara ulaşabilme motivasyonu da taşımaktadır (Meethan, 2008, s. 100). Soy izi turizminin gelişmesine özellikle internet teknolojilerindeki gelişmelere bağlı olarak ortaya çıkan dijital kayıtların katkı sağladığı belirtilmektedir (Meethan, 2004, s. 139). Baz1 ülkelerde nüfusla ilgili tutulan kayıtların dijital ortama aktarılarak erişime açılması pek çok insan için aile soy ağacını öğrenme firsatı sunarken, insanların soy izlerini takip etme, yerinde görme ve deneyimleme amaciyla seyahat etmelerine neden oluşturmaktadır. Bununla beraber, dijital arşiv kayıtlarının erişilemediği ya da yetersiz kaldığ1 durumlarda ise, soy izi turistleri birincil elden bilgi ve belge toplamak amaciyla ulusal veya uluslararası seyahatlere çıkabilmektedir. Soy izi turizminin ilk örnekleri İngiltere Turizm Birliği’nin 1999 yılında tüm dünyadaki İngiliz kökenli insanların, geçmişlerinin izini sürmek amacıyla İngiltere'yi ziyaret etmelerini teşvik amacıyla başlattığı kampanyada görülmektedir (Birtwistle, 2005, s. 60).

Atasoy turizmi kapsamında yer alan bir diğer turizm türü ise bu çalşmanın da ana konusunu oluşturan atayurt turizmidir. Atayurt turizmi, geçmişte ataların yaşadığı bölgelere yönelik yapılan turizm faaliyetlerini kapsamaktadır (Mehtiyeva ve Prince, 2020, s. 86). İnsanların nostalji duygusuyla hareket ederek atalarından kalan hiç görmedikleri "evlerini”" ziyaret etme sürecini ifade eden atayurt turizmi (Sim ve Leith, 2013, s. 260), ziyaretçilerin kimlik, kültür ve aidiyet algilarına etki etmektedir (Bhandari 2016: 925). Bu nedenle, atayurt seyahatleri geçmişe yönelik manevi bir yolculuk, bir keşif yolculuğu, mistik bir eve dönüşs süreci ve yaşam boyu sürecek bir tecrübe olarak ifade edilmektedir (Basu, 2004, s. 154).

Göç yoluyla terk edilen bölgeye yönelik seyahat motivasyonları, kuşaklar ilerledikçe bireysel hatıra ve anılardan, uzak geçmişe yönelik özlem, nostalji ve kültürel aidiyete doğru evrilmektedir (Methiyeva ve Prince, 2020, s. 86). Bu bakımdan geçmişle duygusal bağ kurma ve kültürel kimlik duygusunun pekiştirilmesi amaciyla yapılan atayurt seyahatleri (Marschall, 2015, s. 880), insanlara nereden geldiklerini ve köklerinin nereye dayandığını hatırlatmaktadır (Bhandari, 2016, s. 917). Atayurt turizmi bu yönüyle, bireylerin kendini inşa etme ve anlamlandırma sürecinde geçmişten yararlanmasını sağlamaktadır. İnsanların bireysel ve kültürel aidiyetleri arasında bağ kurarak, varlık sebeplerini kültürel zeminde yeniden 
yorumlamalarına yardımcı olmaktadır. Bu yönüyle atayurt turizmi, birey ve kültür arasında bir köprü kurmaktadır (Bryce, Murdy ve Alexander, 2017, s. 51).

Bir ulusun tarihi mirası, ulusal kimlik oluşturmak için kullanılan en önemli unsurlardan biridir. Miras turizminin ulusal kimliğin sembolik temsillerini deneyimleme rolü göz önüne alındığında, bu aynı zamanda Atayurt ziyaretçilerine "ulusa ait olmalarını tasarlama, hayal etme ve onaylama" firsatı da sunmaktadır (Park, 2010, s. 119). Bu bakımdan, atayurt turizminin ortak bilinç yaratan ve bağdaştırıcı mesajları, o ulus içindeki üst kimlik algısını ve aynı şekilde o ulusun başkaları tarafından da nasıl algıllandığını etkilemektedir (Palmer, 1999, s. 2). Ata mirasını önceleyen turizm hareketlerinin aynı zamanda geçmişle bağın kopması sonucu yaşanan kültürel yabancılaşma ve toplumsal kimlik özelliklerinden uzaklaşma sürecini yavaşlatıp tersine çevirebileceği de vurgulanmaktadır (Bulut ve Gülcan, 2018, s. 688).

Atayurt ve soy izi turizm türleri, bireyin algılladığı ve kimliğiyle ilişkilendirdiği gerçek ata mirasını aramasıyla doğan turizm çeşitleri olarak post-modern miras turizminin bir parçası olarak değerlendirmekte ve günümüz turizm pazarı içerisinde önemli bir payı oluşturmaktadır (Birtwistle, 2005, s. 59).

\section{Atayurt Turizm Ürünü ve Pazarı}

Turist davranışını anlamak, başarılı bir turizm ürünü geliştirebilmenin en önemli koşulu olarak ifade edilmektedir (Johns ve Gyimóthy, 2002; Pizam ve Sussmann, 1995). Bu nedenle atayurt turizminin arz ve talep özelliklerinin destinasyon paydaşları tarafindan anlaşlması, bu turizm ürününün doğru şekilde planlanabilmesi bakımından gereklidir. Atayurt pazarında ziyaretçi motivasyonu diğer turizm türlerinden, özellikle de kitle turizminden oldukça farklıdır. Atayurt ziyaret deneyimi, "eve dönme" duygusu içerdiği için, özellikle bu duygunun ziyaretçilere yaşatılması oldukça önemlidir. Atayurt ziyaretçilerinin turist yerine "ev sahibi" muamelesi görmek istemeleri ve yerel yaşam uygulamalarını ve gelenekleri yerel halkla deneyimleme beklentileri bu pazarın en ayırt edici özelliğidir. Bu beklentinin karşılanması, destinasyon paydaşlarının ortak çabasını ve özellikle yerel halkla iş birliğini gerekli kılmaktadır.

Atayurt ziyaretçileri, masa başında elde ettiği bilgilerden çok daha fazlasına ulaşmak ve bunları yaşayarak deneyimlemek amacındadır. Atayurt turizminde arkeolojik alanlar, doğal çevre ve kültürel merkezler ile mitler, hikâyeler ve efsaneler talebin ana kaynağ1 konumundadır. Bu nedenle, doğru belirlenmiş gezi rotaları ve konuyla ilgili uzman rehberlerin varlığ1 oldukça mühimdir. Atayurt ziyaretçilerinin geçmişle bağ kurup, aidiyet duygusunu yaşayabilmeleri adına destinasyon örgütlerinin talep edilen hizmet, ürün ve deneyimlerle ilgili tatmin edici seçenekler sunması beklenmektedir (Scottish Enterprise, 2020).

Fordist anlayış sonrası bireyselleştirilmiş ürünlere yönelik talebin artmasına bağlı olarak pek çok destinasyon, ürün çeşitliliğini arttırmak ve yüksek katma değer yaratmak amacıyla niş pazarlara odaklanmıştır (Hall, 1999; Lew, 2008). Atayurt turizm pazarı da tüm dünyada hızla gelişmekte olan önemli bir niş pazar olarak belirtilmektedir. Atayurt turizmi özellikle finansal ve zaman kaynakları açısından varlıklı kabul edilen pazarlarda, miras turizminin en hızlı büyüyen bölümleri arasındadır. Bununla beraber, atayurt turizmi günümüzde bazı ülkelerde niş pazar boyutunu aşarak neredeyse kitle turizm hareketliliği düzeyine ulaşırken, bazı ülkelerde ise çok az gelişmiş ya da hiç gelişmemiştir (Alexander vd., 2017, s. 543; Caton ve Santos, 2007, s. 371; Li ve McKercher, 2016, s. 106). Bir göçmenler ülkesi olan ABD'de özellikle son birkaç on yıldır insanların geçmişlerini ve kökenlerini araştırması yaygınlık kazanmıştır (Timothy ve Teye, 2004, s. 112). Ayrıca günümüzde özellikle Kuzey Amerika ülkelerinden ve Avustralya’dan İskoçya, İrlanda, İsrail ve Afrika'ya yönelik atayurt turizm hareketliliği, turizm pazarı içerisinde anlamlı bir seviyeye ulaşmışır (Pelliccia, 2018, s. 2109).

Atayurt odaklı artan turizm talebi, bu gelişmeyi fark eden bazı ülkeler tarafindan oldukça iyi yönetilmektedir. İskoçya bu alanda lider ülkelerden biridir. İskoçya Devleti, tüm dünyadaki İskoç asıllı insanları önemli bir turizm pazarı olarak sınıflamış ve pazarlama politikalarında atayurt turizmini geliştirmeyi ana hedef olarak belirlemiştir (Bhandari, 2016, s. 913). Dünyada İskoçya kaynaklı olarak 50 milyon insan olduğu tahmin edilmektedir. Bu ülkede atayurt turizmi, en büyük şehirlerden en uzak kırsal topluluklara kadar ülkenin tüm bölgelerine fayda sağlayacak bir firsat olarak planlanmakta ve uygulanmaktadır. Atayurt turizmi ile İskoçya'nın turizm işletmeleri için 2,4 milyar $f$ yaratma potansiyeli olduğu bildirilmekte ve gelecek beş yilda bu pazarın 800.000 ziyaretçiden 4,3 milyon ziyaretçiye kadar önemli bir büyüme potansiyeline ulaşacağı öngörülmektedir (Scottish Enterprise, 2020). 
Atayurt turizminde, katılımcıların harcamaları ortalama bir ziyaretçiden daha fazla, kalış süreleri diğer ziyaretçilere oranla daha uzun ve destinasyonu başkalarına tavsiye etme oranı da daha yüksek olmaktadır. Örneğin, İskoçya'da ortalama olarak 4,5 geceleme olan kalış süresi, atayurt ziyaretçileri için ortalama 10 gecelemeye çıkmaktadır. Aynı şekilde tavsiye oranı da \%97 düzeyine çıkmaktadır. Bu ziyaretçiler, duygusal bağlantılarının olduğu, atalarının yaşadığı ve atayurt olarak seçtikleri mekânları ziyaret etmektedirler (Scottish Enterprise, 2020; Visit Scotland, 2020).

\section{Atayurt Destinasyonu Olarak Orta Asya Bölgesi}

Doğal ve kültürel zenginlik alanları bakımından benzersiz bir coğrafyaya sahip olan Orta Asya, binlerce yıl boyunca İpek Yolu ile Doğu ve Batı arasında bir köprü görevi görmüştür. Tarihsel, kültürel ve stratejik önemi nedeniyle bölge bugün de pek çok açıdan ilgi çekmektedir. Son dönemlerde modern İpekyolu projesiyle beraber bölge araştırmacilardan, potansiyel yatırımcilardan, tur operatörlerinden ve dolayısıyla ziyaretçilerden daha fazla ilgi görmeye başlamıştır. Bu gelişmeler Orta Asya ülkelerinin turizm gelişimi için oldukça önemli olmakla beraber, bölgenin sahip olduğu turizm potansiyelinin gerçeğe dönüştürülmesi iyi planlanmıs, uzun ve pahalı bir sürece ihtiyaç duymaktadır (Hiro, 2009, s. 22; Kantarc1, 2007a, s. 821; Kantarc1, Uysal ve Magnini, 2014, s. 1).

Orta Asya Bölgesi batıda Hazar Denizi'nden, doğuda Çin'e, kuzeydeki merkezi Sibirya'dan güneyde Afganistan, İran ve Pakistan'a kadar uzanmaktadır. Orta Asya ülkelerinden Kazakistan 19,9 milyon nüfusa ve 2,7 milyon $\mathrm{km}^{2}$ alana, Kırgızistan 5,9 milyon nüfus ve 199,9 bin $\mathrm{km}^{2}$ alana, Türkmenistan 5,5 milyon nüfus ve 488,1 bin $\mathrm{km}^{2}$ alana, Özbekistan 30,5 milyon nüfus ve 447,4 bin $\mathrm{km}^{2}$ alana ve Tacikistan 8,8 milyon nüfus ve 144,1 bin $\mathrm{km}^{2}$ alana sahiptir. Bölge toplamda yaklaşık 4 milyon $\mathrm{km}^{2}$ yüzölçümüne ve 70,6 milyon nüfusa ev sahipliği yapmaktadır (Britannica, 2020). Orta Asya ülkeleri topografya, iklim, tarih, kültür ve ekonomik kalkınma bakımından çeşitlilik göstermektedir.

Özgün yapısına rağmen Orta Asya bölgesinde turizm gelişimi halen oldukça sınırlı düzeydedir. Turizmin küresel gayrisafi hasılaya katkısı \%10,3 dolayında iken, bu oran Orta Asya ülkeleri için \%5,2 düzeyinde gerçekleşmektedir. Bölge ülkeleri 2018 yılında toplamda 23 milyon dolayında ziyaretçi alırken, bölgedeki toplam ziyaretçi harcamaları ise 5,1 milyar Amerikan doları seviyesinde gerçekleşmiştir (Dünya Turizm Örgütü, 2020). Turizmin küresel olarak geldiği seviye göz önüne alındığında, Orta Asya bölgesinin sahip olduğu özgün potansiyeline rağmen bunun uzağında kaldığı ifade edilebilir. Bölge ülkelerinin seçili yıllara göre aldıkları ziyaretçi sayıları Tablo 1'de gösterilmektedir.

Tablo 1. Yullara Göre Orta Asya Ülkelerinin Aldı̆ğ Ziyaretçi Sayzlar

\begin{tabular}{llllll}
\hline Ülkeler & $\mathbf{2 0 0 0}$ & $\mathbf{2 0 0 5}$ & $\mathbf{2 0 1 0}$ & $\mathbf{2 0 1 5}$ & $\mathbf{2 0 1 8}$ \\
\hline Kazakistan & $1,683,000$ & $4,365,000$ & $4,097,000$ & $6,430,000$ & $8,789,000$ \\
Kirgizistan & 173,000 & 319,000 & $1,224,000$ & $4,000,000$ & $6,947,000$ \\
Moğolistan & 158,000 & 345,000 & 557,000 & 467,000 & 598,000 \\
Özbekistan & 302,000 & 242,000 & 975,000 & $1,918,000$ & $5,346,000$ \\
Tacikistan & 8,000 & - & 160.000 & 414.000 & $1,035,000$ \\
Türkmenistan & 3,000 & 12,000 & - & - & - \\
\hline
\end{tabular}

Kaynak: Dünya Turizm Örgütü, 2020

Orta Asya ülkelerine gelen ziyaretçi sayıları büyük ölçüde bölge içinden gerçekleşmektedir. 2016-2018 yılları arası bölgeye girişlere bakıldığında; Kazakistan \%36, Özbekistan \%26, Rusya Federasyonu \%19, Kırgızistan \%10, Türkiye \%1 olarak ilk beş içinde yer almaktadır. Diğer ülkeler toplamı ise $\% 8$ olarak gerçekleşmektedir (Dünya Turizm Örgütü, 2020). Bu veriler bölgenin uluslararası turizm pazarılla yeterince bütünleşemediğini ve küresel bir destinasyon haline gelemediğini göstermektedir.

Orta Asya bölgesi için atayurt turizmi pek çok açıdan geliştirilmesi gereken oldukça önemli bir turizm türüdür. İlk olarak bu turizm türü Orta Asya coğrafyasının rekabette en güçlü olduğu turizm alanıdır. Çünkü bu coğrafya, Türk ulusu için tek olmasa da en önemli coğrafyadır ve alternatifi bulunmamaktadır. Türklerin tarih sahnesine çıktıkları ilk yurtları, yazılı ilk kaynakları, kurdukları ilk devletleri ve en eski mitolojik hikâyeleri Orta Asya coğrafyasında yer almaktadır. Bu bakımdan atalarının izini ve kültürünü arayan her Türk'ün ulaşması gereken ilk ve en eski kaynak Orta Asya coğrafyasıdır. İkincisi, atayurt ziyaretçileri normal bir turistten daha uzun geceleme ve daha fazla harcama yapmaktadır (Iorio ve Corsale, 
2013). Bu yönüyle atayurt turizmi, bölgeye diğer turizm çeşitlerinden daha fazla ekonomik katk1 yapma potansiyeline sahiptir. Üçüncü olarak, atayurt turizm faaliyetleri yılln tamamına yayılma özelliği göstermektedir. Bu durum ise, sezonluk gelişen turizm türlerine göre, atayurt turizminin istihdam ve ekonomik hacim yaratmada bölgeye önemli bir avantaj sağlayabileceğini göstermektedir. Dördüncü olarak, atayurt turizmi hareketliliği kapsamında değerlendirilebilecek mekân ve varlıklar bölgenin her tarafina yayıldığı için bölgenin tamamının bu hareketlilikten yararlanması mümkün olacaktır. $\mathrm{Bu}$ ise bölge ülkelerinin atayurt turizmini geliştirmede iş birliği yapmalarını teşvik etmektedir. Beşinci olarak ise, bu turizm faaliyeti için geliştirilen hizmet, mekân ve varlıklar aynı zamanda yerel toplulukların da yararlanması için anlamlı firsatlar sunmaktadır. Bununla beraber, bu çekicilikler diğer turizm türleri ve motivasyonları için de farklı boyut ve oranlarda temel veya ürün bileşeni haline dönüşerek ilave değer yaratabilmektedir. Son olarak, atayurt turizm hareketliliği Orta Asya'daki Türk tarihi, kültürü, inançları, gelenekleri ve doğasının envanterinin çıarılması, güçlendirilmesi ve sürdürülebilir bir şekilde yönetilmesi için gerekli motivasyonun oluşmasına ve finansman kaynağının sağlanmasına da yardımcı olacağı öngörülmektedir.

Orta Asya bölgesi Türk tarihi açısından oldukça önemli olan soyut ve somut miras varlıklarına ev sahipliği yapmaktadır. Bu soyut ve somut miras varlıklarının atayurt turizmi ve diğer ilgili turizm türleri talebine göre ürün yapılarına ilave edilmesi, sunulması, günümüz teknolojilerinden yararlanarak dijital ortama aktarılmas1, edebiyat, sanat, sinema, fotoğraf ve video malzemesine çevrilerek temel ürün veya ürün bileşenleri olarak uygulanması oldukça geniş ve önemli bir çalışma alanıdır. Bu çalısmaların başarı düzeyinde bölgedeki kültür ve yaratıcı endüstrilerin kapasitesi ve uluslararası iş birliği yeteneği belirleyici olmaktadır (Kantarc1, 2007b, s. 57; Yessenova 2014, s. 173).

\section{Orta Asya Atayurt Turizmi İçin Türkiye Pazarı}

Türkiye Türkleri için atayurt turizmi hedef coğrafyası olarak Orta Asya'nın seçilmesinin hem tarihsel hem de bugünkü koşullardan kaynaklanan çeşitli nedenleri bulunmaktadır. Bu gerekçeler aynı zamanda coğrafya pazarlaması ile de ilişkilidir. İki bölge arasındaki fiziksel ve kültürel mesafenin turistlerin destinasyon tercihinde etkili olduğu belirtilmektedir (Kastenholz, 2010). Özellikle kültürel yakınlık, aşinalık ve benzerliğin ziyaretçilerin diğer ülkeyi görme biçimini ve dolayısıyla seyahat tercihini anlamlı düzeyde etkilediği belirtilmektedir (Huang, Chen ve Lin, 2013; Kantarc1, 2007c, s. 308). Ortak kültür ve tarih nedeniyle Türkiye ile Orta Asya ülkeleri arasında arz ve talep bakımından en kolay geliştirilebilecek turizm çeşidi atayurt turizmidir. Ayrıca, Türk kültürünün en belirgin özelliğinin başında aile ve akraba ilişkilerine önem vermesi ve atalarına ve köklerine bağlllık gelmektedir. Bu özellik ise atayurt turizminin ihtiyaç duyduğu ana motivasyon kaynağını oluşturmaktadır.

Türkiye, Orta Asya coğrafyasından yüzylllar içerisinde çeşitli nedenlerle meydana gelen göçler sonucunda Türkler tarafından yurt edinilen ve 2020 nüfus tahmini 82 milyon olan bir ülkedir. Bugünkü Türkiye coğrafyası 1071 yılından çok daha önceleri Türk topluluklarının yaşam alanı olarak seçtiği bir bölge olmakla beraber, buraya büyük kitleler halinde yerleşmeler çoğunluğu Oğuz Türkmen yapılarından oluşan Selçuklu İmparatorluğu ve Anadolu Selçuklu Devleti dönemlerinde gerçekleşmiştir (Ortayli, 2016, s. 72141).

"Türk" kelimesi bir devlet adı olarak ilk defa Orta Asya'da kurulan ve zamanının en büyük devletlerinden biri haline gelen KökTürk/Göktürkler tarafından kullanılmıştır. İlk yurtlarının Altay Dağlarının güney etekleri olduğu bilinen Göktürklerin, bugün dünya tarihinde Türkler ele alındığında çok önemli bir yeri olduğu belirtilmektedir. Bununla beraber Orta Asya Bölgesi, Hunlara ve pek çok Türk boyuna ev sahipliği yapmıştır. En eski Türk yurdunun ise Yenisey Irmağının çıkış yerleri olduğunu arkeolojik kanıtlar desteklemektedir (Taşağıl, 2017, s. 15-42). Türk Dünyasını en çok etkileyen kişilerden biri olan Hoca Ahmet Yesevi'nin kabrinin bulunduğu ve Türk dünyasının ruhani başkenti olarak kabul edilen Türkistan (Yesi), "Şehirlerin Prensesi" olarak kabul edilen Buhara, "Bütün Şehirlerin Kraliçesi" olarak ifade edilen Semerkand, kumlara gömülü miras olan Hive ve Merv gibi sadece Türkler için değil aynı zamanda küresel miras bakımından önemli olan birçok yaşayan miras alanları Orta Asya'da yer almaktadır (Hyman, 1997, s. 319; İslam Ansiklopedisi, 2020; Sazak, 2014; Yücel, 2014). Türk dünyası için oldukça önemli olan Ötüken ve Orhun Anttları da yine bu coğrafya ve çevresi ile ilişkilidir. Bununla beraber, Orta Asya Ülkeleri Kazakistan'da beş, Kırgızistan'da üç, Özbekistan'da beş, Tacikistan'da iki ve Türkmenistan'da üç olmak üzere toplamda onsekiz UNESCO dünya miras listesine girmiş mekâna ev sahipliği yapmaktadır (UNESCO, 2021). Bölge aynı zamanda tarihi İpek Yolu üzerinde olması nedeniyle 
pek çok soyut ve somut miras ürününe sahiptir. Bununla beraber, Türklerin en önemli efsanelerinden biri olan ve Göktürklerde de var olan kurt efsanesi ve Oğuz Kağan Destanı, Ergenekon Destanı, Türeyiş Destanı ve Manas Destanı gibi Türk tarihinin soyut miras zenginlikleri de Orta Asya Türk coğrafyasının ürünleridir (Taşağıl, 2017, s. 44). Bütün bu gerçeklik, Orta Asya bölgesinin Türkiye pazarına sunabileceği anlamlı bir atayurt turizm kaynağı olduğunu göstermektedir.

Türkiye'den yurt dışına giden ziyaretçi sayısı ise 2019 yılında 9,9 milyon iken, yapılan harcama ise 4,4 milyar Amerikan doları olarak gerçekleşmiştir. Bununla beraber, Türkiye'den yurt dışına çıkanların oldukça az bir bölümü Orta Asya ülkelerini ziyaret etmektedir. 2018 yılı verilerine göre Türkiye'den Kazakistan'1 99,351 (pazar pay1 \%1.13), Kırgizistan’1 51,917 (pazar pay1 \%0,75), Özbekistan’1 41,299 (pazar pay1 \%0,77), Tacikistan’1 4.075 (pazar payı \%0,39), ve Moğolistan’1 2,699 kişi (pazar pay1 \%0,51) ziyaret etmiştir. Türkmenistan'a ait verilere ise ulaş1lamamaktadır. Türkiye'den orta Asya Ülkelerine giden ziyaretçi sayısı toplamda 199,341 iken, bu rakam Türkiye'den yurt dişına çıkan vatandaşların sadece \%0,019'unu oluşturmaktadır (Dünya Turizm Örgütü, 2020; Türkiye Seyahat Acenteleri Birliği [TURSAB], 2020). Bu oran Orta Asya Bölgesi için büyük bir potansiyel olan Türkiye pazarının ihmal edildiğini açıkça göstermektedir. Yıllara göre Orta Asya ülkelerini ziyaret eden Türkiye Cumhuriyeti vatandaşları sayıları tablo 2'de gösterilmektedir. Rakamlar, Türkiye'den bölgeye yönelik talebin artma eğiliminde olduğunu gösterse de talebin oldukça az ve artış hızının da oldukça yavaş ilerlediği görülmektedir.

Tablo 2. Yillara Göre Orta Asya Ülkelerini Ziyaret Eden Türkiye Cumburiyeti Vatandaşlar Sayısı

\begin{tabular}{llllll}
\hline Ülkeler & $\mathbf{2 0 0 0}$ & $\mathbf{2 0 0 5}$ & $\mathbf{2 0 1 0}$ & $\mathbf{2 0 1 5}$ & $\mathbf{2 0 1 8}$ \\
\hline Kazakistan & 17,721 & 58,034 & 52,276 & 106,301 & 99,351 \\
Kirgzistan & 3,176 & 9,362 & 11,523 & 36,139 & 51,917 \\
Moğolistan & 351 & 513 & 1,157 & 2,421 & 2,699 \\
Özbekistan & - & - & - & 36,256 & 41,299 \\
Tacikistan & 110 & - & 1,441 & 3,169 & 4,075 \\
Türkmenistan & 98 & 119 & - & - & - \\
\hline Toplam & 21,456 & 68,028 & 66,397 & 184,286 & 199,341 \\
\hline
\end{tabular}

Kaynak: Dünya Turizm Örgütü, 2020

Yapılan bazı çalışmalarda (Kantarcı, Başaran ve Özyurt, 2017, s. 308), Orta Asya’yı ziyaret eden Türklerin temel motivasyonlarının bölge tarihi ve Orta Asya ve Türkiye arasındaki benzerlik ve aşinalık olduğu ifade edilmektedir. Bununla beraber, bu ziyaretlerin miras ve atayurt turizmi adı altında geliştirilmesi, pazarlanması ve yönetilmesi henüz ne Türkiye pazarı ne de Orta Asya turizm endüstrisi paydaşları tarafindan yeteri kadar anlaşılamamış ve bu nedenle Türkiye'den bu bölgeye yönelik turizm talebi oldukça düşük seviyede ve münferit olarak gerçekleşmektedir. Turizmin küresel olarak gelişme dönemlerinde, bölgenin uzun süre Sovyet yönetimi altında kalması nedeniyle dış dünya ile iletişimi sınırlı olmuştur ve gelişmelerden yararlanamamıştır. $\mathrm{Bu}$ nedenle bölge ülkeleri kendi turizm pazarlama stratejilerini oluşturmakta geç kalmıştır. Türkiye'nin ise büyük oranda deniz, güneş, kum kaynaklarına dayalı organize kitle turizmine öncelik vermesi nedeniyle atayurt turizmi gibi kültür odaklı turizm türlerine yeterince yönelememesi de bir başka etken olarak ifade edilebilir.

\section{Sonuç ve Öneriler}

Bu çalışmada küresel ölçekte önemli bir pazar haline gelen soy bilimsel odaklı turizm türlerinin Türkçede kullanılabilecek kavram karşılıkları geliştirilmiştir. Bu alanın Türkçe alanyazına kazandırılması Türk Dünyası içerisindeki turizm hareketliliği için oldukça yeni ve farklı bir alternatif sunmaktadır. Bu turizm türlerinin aynı zamanda kültür, varlık ve miras algısı üzerine yaptı̆̆ı kalıcı etkiler bu alanın çok boyutlu olarak değerlendirilmesini gerekli kılmaktadır.

Tarihte pek çok Türk ve akraba topluluklara yurt olan Orta Asya bölgesi, Türk kimliğinin en güçlü temsil edildiği coğrafyadır. Bölgenin hemen her tarafina yayılmış, yeraltı ve yer üstündeki soyut ve somut miras zenginlikleri atayurt turizm ürünü haline dönüştürülerek turizm pazarına arz edilmeyi beklemektedir. Orta Asya bölgesinin sahip olduğu atayurt turizm varlıklarının ürün haline dönüştürülmesi, pazarlanması ve yönetilmesi çok boyutlu ve uzun dönemli bir planlama sürecine ihtiyaç duymaktadır (Kantarcı et al. 2014, s. 1). Bölgedeki kültür varlıklarının önemli bir kısmı, turizm altyap1 ve üst yapısı ve pazarlama 
sistemleri belli bir seviyede işler haldedir. Fakat bunların atayurt turizmi kapsamında yeniden ele alınması, destinasyon örgütlerinin ve karar alıcıların planlama sürecinde öncelikle değerlendirmesi gereken konuların başında gelmektedir. Bölgenin özgün kaynak bağlamında en güçlü olduğu bu turizm alanının geliştirilebilmesi için atayurt turizm farkındalığının arttırılması ve turizm politika ve planlama süreçlerinde buna yer verilmesi gerekli ve önemli olarak görülmektedir.

Küreselleşmeyle beraber tüm sektörler daha rekabetçi bir yapıya dönüşmektedir. Turizm talebindeki eğilimler, günümüzdeki yoğun rekabet koşullarında başarllı olmanın yeni pazarlar yaratmaya bağlı olduğunu göstermektedir. Destinasyonların rekabet edebilir ve sürdürülebilir turizm ürünleri yaratma sürecini, sahip oldukları özgün kaynaklara göre düzenlemeleri önerilmektedir (Augustin ve Liaw, 2017, s. 1295; McCain ve Ray, 2003, s. 714). Bu bakımdan, Orta Asya ülkelerinin rekabette en güçlü olduğu turizm alanı olan atayurt turizmi bölge için stratejik önemdedir. Bu yönüyle destinasyon örgütlerinin, atayurt pazarını tanımaları ve buna uygun arz çalışmaları yürütmeleri var olan bu potansiyelden bölge için katma değer yaratma adına oldukça önemlidir.

Bu çalşsma atayurt turizmi ile ilgili temel kavramları ifade etmekte, ürünün arz ve talep tarafi ile ilgili yapıları tanımlamakta ve bu alandaki firsat ve potansiyeli ele almaktadır. Bu aşamada, bölgede atayurt turizm arzının geliştirilmesi ve talep yaratılması süreçlerinde, bölge ülkeleri ile Türkiye'nin iş birliği yapması önemlidir. Bu süreç, bir turizm faaliyeti olmasının yanı sıra, Türkiye ile bölge ülkelerinin kültürel, ekonomik ve siyasi iş birliğine de olumlu katkılar sağlayabilir. Bu nedenle hem Orta Asya ülkelerinde hem de Türkiye'de bireysel ve kurumsal düzeyde atayurt turizm farkındalığının arttırllmasının, bu iş birliği ve turizm alanının hızla gelişmesini teşvik edebilir.

Türk kültürü çok yönlü, zengin ve geniş coğrafyaya sahip bir özelliktedir. Bu nedenle, sayısız zenginliğe sahip Türk dünyasının hangi kişileri, mekânları, olayları, soyut ve somut mirasın hangi yönleri atayurt turizmi ürünü olarak çalı̧acağı önemli bir konudur. M.Ö. 4.000'den itibaren başladığı belirtilen Türk tarihinin mekânları elbette Orta Asya ile sınırlandırılamaz. Zaman içerisinde 16 büyük imparatorluk ile birlikte farklı boyutlarda yüzlerce devlet kuran Türk ve akraba toplulukların 3 kıtaya yayılmış olağanüstü mekanları ve mirasları ata yurt turizmi için eşsiz çekicilikler oluşturmaktadır (Günay, 2012, s. 20). Atayurt odaklı yapılan bu çalısma Orta Asya bölgesine odaklanırken, Türk tarihi açısından önemli olan diğer coğrafyaları inceleyen atayurt turizmi çalışmalarının yapılması da gerekli görülmektedir. Farklı Türk coğrafyalarının sahip olduğu ata mirasını ürüne dönüştürecek çalışmalar, bölgesel kalkınma ve Türk miras varlıklarının korunması ve az bilinen bölgelere yönelik duyarlılığı artması noktasında önemlidir. Bununla beraber, atayurt turizminin, arz ve talep koşulları yönünden farklı boyutlarının araştırılması, bu alanın hem akademide hem de uygulamada gelişmesine yardımcı olacaktır.

Atayurt turizm kaynaklarının geliştirilmesi Orta Asya bölgesi için bir turizm ürünü olmasının yanı sıra, bölge ülkelerinin aynı zamanda imaj geliştirme ve kaynakların sürdürülebilirliğinin sağlanması adına da oldukça önemlidir. Bu turizm türü ortak imaj ve diğer düzenleyici faktörler bakımından bölge ülkelerinin iş birliğini gerekli kılmaktadır. Bölge ülkelerinin atayurt destinasyonu olarak bu turizm hareketliliği için sunacağı mekân ve varlıkların, bütünün parçaları şeklinde planlanması ve geliştirilmesi bölge ülkelerinin iş birliği yapma yeteneklerinin geliştirilmesine de katkı sağlayacaktır.

Çalışma Orta Asya ve Türkiye bağlamında atayurt turizmi için olduğu kadar, aynı zamanda küresel turizm pazarı için etnik turizm ve miras turizmi türleri bakımından da önemli bir arz alanı yaratmaktadır. Bölgede atayurt turizmi ürün, çekicilik ve rotaların geliştirilmesi, bunların aynı zamanda dünya turizm pazarına açılmasını da sağlayacaktır. Dünya genelinde kültür ve mirasa ilgi duyan ve miras motivasyonuyla seyahat edenlerin sayısı düzenli olarak artmaktadır (Richards, 2018). Orta Asya bölgesinde geliştirilecek atayurt turizm hareketliliği, aynı zamanda miras alanlarına ilgi duyan pek çok milletten insanın bölgeyi ziyaret etmesini sağlayabilir. Bu ise, uluslararası turizm pazarında bölgenin bir miras turizm destinasyonu olarak gelişmesini teşvik edebilir.

\section{Etik Beyan}

"Kimlike. Arayışında Yeni Bir Ë̆lim: Orta Asya'da Atayurt Turižmi” başlıklı çalışmanın yazım sürecinde bilimsel kurallara, etik ve alıntı kurallarına uyulmuş; toplanan veriler üzerinde herhangi bir tahrifat yapılmamış ve bu çalışma herhangi başka bir akademik yayın ortamına değerlendirme için gönderilmemiştir. Bu araştırma doküman incelemesine dayalı olarak yapıldığından etik kurul kararı zorunluluğu bulunmamaktadır. 


\section{Teşekkür}

Çalışma kapsamında ihtiyacımız olan Orta Asya ülkeleri turizm verilerini ücretsiz şekilde bizimle paylaşan Dünya Turizm Örgütü’ne teşekkürlerimizi iletiyoruz.

\section{Kaynakça}

Alexander, M., Bryce, D. ve Murdy S. (2017). Delivering the past: Providing personalized ancestral tourism experiences. Journal of Travel Research, 56(4), 543-555.

Augustin, J.-L. M. A. ve Liaw, S.-Y. (2017). Tourism competitiveness index of the Asia-Pacific region through consistency analysis. Asia Pacific Journal of Tourism Research, 22(12), 1295-1307.

Basu, P. (2004). Route metaphors of roots tourism in the Scottish highland diaspora. İçinde; S. Coleman ve J. Eade (Edt.) Reframing pilgrimage: cultures in motion (ss. 150-174). Londra: Routledge.

Bhandari, K. (2016). Imagining the Scottish Nation: tourism and homeland nationalism in Scotland. Current Issues in Tourism, 19(9), 913-929.

Birtwistle, M. (2005). Genealogy tourism-the Scottish market opportunities. İçinde; M. Novelli (Edt.) Niche Tourism: Contemporary ussues, trends and cases (ss.73-86). Oxford: Elsevier.

Britannica (2020). Central Asia. https://www.britannica.com/place/Central-Asia\#ref321593 (Ziyaret tarihi: 25.09.2020).

Bryce, D., Murdy S. ve Alexander M. (2017). Diaspora, authenticity and the imagined past. Annals of Tourism Research, 66, 49-60.

Bulut, Y. ve Gülcan B. (2018). Kültürel yabancılaşmaya bağlı otantiklik arayışına Türk Dünyası turizmi cephesinden bakış. MANAS Sosyal Araștırmalar Dergisi, 7(4), 687-702.

Caton, K. ve Santos C. A. (2007). Heritage tourism on route 66: Deconstructing nostalgia. Journal of Travel Research 45(4), 371-386.

Dünya Turizm Örgütü (2020). Yearbook of Tourism Statistics, 2020 Edition. Madrid, DOI: http://doi.org/10.18111/9789284421442.

Günay, U. T. (2012). Türklerin tarihi: Geçmişten geleceğe. İstanbul: Akçağ Yayınları.

Hall, D. (1999). Destination branding, niche marketing and national 1mage projection in Central and Eastern Europe. Journal of V acation Marketing, 5(3), 227-237.

Higginbotham, G. (2012). Seeking roots and tracing lineages: Constructing a framework of reference for roots and genealogical tourism. Journal of Heritage Tourism, 7(3), 189-203.

Hiro, D. (2009). Inside Central Asia: A political and cultural history of Uzbekistan, Turkmenistan, Kazakbstan, Kyrgyzstan, Tajikistan, Turkey, and Iran. New York: Overlook Press.

Huang, W., Chen, C. ve Lin, Y. (2013). Cultural proximity and intention to visit: Destination image of Taiwan as perceived by mainland Chinese visitors. Journal of Destination Marketing \& Management, 2(3), 176-184.

Hyman, A. (1997). Turkestan and panTurkism revisited. Central Asian Survey, 16(3), 339-351.

Iorio, M. ve Corsale A. (2013). Diaspora and tourism: Transylvanian Saxons visiting the homeland. Tourism Geographies, 15(2), 198-232.

İslam Ansiklopedisi (2020). Ahmet Yesevi külliyesi. https://islamansiklopedisi.org.tr/ahmed-yesevi-kulliyesi (Ziyaret tarihi: 14.05 .2020$)$.

Johns, N. ve Gyimóthy S. (2002). Market segmentation and the prediction of tourist behavior: The case of Bornholm, Denmark. Journal of Travel Research, 40(3), 316-327.

Kantarc1, K. (2007a). Perceptions of foreign investors on the tourism market in Central Asia including Kyrgyzstan, Kazakhstan, Uzbekistan, Turkmenistan. Tourism Management, 28(3) 820-829.

Kantarc1, K. (2007b). Perceptions of Central Asia travel conditions: Kyrgyzstan, Kazakhstan, Uzbekistan, and Turkmenistan. Journal of Hospitality \& Leisure Marketing, 15(2), 55-71.

Kantarc1, K. (2007c). The image of central Asia Countries: Kyrgyzstan, Kazakhstan, Uzbekistan, and Turkmenistan. Tourism Analysis, 12(4), 307-318.

Kantarc1, K., Uysal M. ve Magnini V. (2014). Exploring tourism potential in Central Asia. İçinde; K. Kantarc1, M. Uysal ve V. Magnini (Edt.) Tourism in Central Asia: Cultural potential and challenges (ss. 1-14). Ontario: Apple Academic Press.

Kantarcı, K., Başaran, M. A. ve Özyurt, P. M. (2017). Comparative analysis of Central Asian tourism product from point of view of Turkish travelers: A case of Kyrgyzstan, Kazakhstan, Tajikistan, Uzbekistan and Turkmenistan. İçinde: A. H. Gencer, İ. Sözen ve S. Sar1 (Edt.) Eurasian Economies in Transition (ss. 339-357). Newcastle: Cambridge Scholars Publishing.

Kastenholz, E. (2010). Cultural proximity as a determinant of destination image. Journal of V acation Marketing, 16(4), 313-322.

Lew, A. (2008). Long tail tourism: new geographies for marketing niche tourism products. Journal of Travel \& Tourism Marketing, 25(3-4), 409-419. 
Li, T. E. ve McKercher, B. (2016). Developing a typology of diaspora tourists: return travel by Chinese immigrants in North America. Tourism Management, 56, 106-113.

Marschall, S. (2015). Homesick tourism: memory, 1dentity and (be) longing. Current Issues in Tourism, 18(9), 876-892.

McCain, G. ve Ray N. (2003). Legacy tourism: the search for personal meaning in heritage travel. Tourism Management 24(6), 713-717.

Meethan, K. (2004). To stand in the shoes of my ancestors: tourism and genealogy: tourism and genealogy getting connected: Mobility, home and self. İçinde: T. Coles ve T. Dallen (Edt.) Tourism, diasporas and space (ss. 153-164). Londra: Routledge.

Meethan, K. (2008). Remaking time and space: The internet, digital archives and genealogy. İçinde: T. Dallen ve G. Jeanne (Editörler) Geography and genealogy: Locating personal pasts (ss. 99-112). Cornwall: Ashgate.

Mehtiyeva, A. ve Prince S. (2020). Journeys of research, emotions and belonging: An exploratory analysis of the motivations and experience of ancestral tourists. Scandinavian Journal of Hospitality and Tourism, 20(1), 85-103.

Murdy, S., Alexander M. ve Bryce D. (2018). What pulls ancestral tourists 'home'? An analysis of ancestral tourist motivations. Tourism Management, 64, 13-19.

Nuryanti, W. (1996). Heritage and postmodern tourism. Annals of Tourism Research, 23(2), 249-260.

Ortaylı, İ. (2016). Türklerin taribi. İstanbul: Timaş Yayınları.

Palmer, C. (1999). Tourism and the symbols of identity. Tourism Management, 20(3), 313-321.

Park, H. (2010). Heritage tourism: Emotional journeys into nationhood. Annals of Tourism Research, 37(1), 116-135.

Pelliccia, A. (2018). In the family home: Roots tourism among Greek second generation in Italy. Current Issues in Tourism, 21(18), 2108-2123.

Pizam, A. ve Sussmann S. (1995). Does nationality affect tourist behavior? Annals of Tourism Research, 22(4), 901-917.

Richards, G. (2018). Cultural tourism: A review of recent research and trends. Journal of Hospitality and Tourism Management, 36, 12-21.

Santos, C. A. ve Yan G. (2010). Genealogical tourism: A phenomenological examination. Journal of Travel Research, 49(1), 56-67.

Sazak, G. (2014). Bukhara: The princess of cities. İçinde: Kantarci, K., Uysal, M. ve Magnini, V. (Edt). Tourism in Central Asia: Cultural potential and challenges (ss. 67-91). Toronto: Apple Academic Press.

Scottish Enterprise. (2020). Ancestral Tourism. https://www.scottish-enterprise-mediacentre.com/news/ancestraltourism-has-potential-to-create-24-billion-for-scotlands-tourism-businesses (Ziyaret tarihi: 30.12.2020).

Sim, D. ve Leith M. (2013). Diaspora tourists and the Scottish Homecoming 2009. Journal of Heritage Tourism, 8(4), 259-274.

Tan, E. ve Bakar B. A. (2018). Ethnic reunions in tourism: The route to roots. İçinde: E. Yang ve C. Lattimore (Edt.), Asian cultures and contemporary tourism (ss. 21-39). Singapore: Springer.

Taşağıl, A. (2017). Türk model devleti Gök Türkler. İstanbul: Bilge Kültür Sanat.

Timothy, D. (1997). Tourism and the personal heritage experience. Annals of Tourism Research, 24(3), 751-754.

Timothy, D. ve Schmidt K. (2011). Personal heritage and return visits to American colonies in Mexico. Tourism Review International 14(4), 179-188.

Timothy, D. ve Teye V. (2004). American children of the African diaspora. İçinde: T. Colles ve T. Dallen (Edt.) Tourism, Diasporas and space (ss. 125-137). Londra: Routledge.

TURSAB (2020). Turist Say1s1 ve Turizm Geliri. https://www.tursab.org.tr/istatistikler/turist-sayisi-ve-turizm-geliri (Ziyaret tarihi: 18.05.2020).

Türk Dünyas1 Parlamenterler Birliği (2021). Dünyada ne kadar Türk var? https://www.tdpb.org.tr/post/d\%C3\%BCnyada-ne-kadar-t\%C3\%BCrk-var (Ziyaret Tarihi: 01.12.2021).

UNESCO (2021). World Heritage List. https://whc.unesco.org/en/list/\&order=country (Ziyaret Tarihi: 01.12.2021)

United States Census Bureau. (2018). American community survey 1-year estimates. https://data.census.gov/cedsci/table?t=Ancestry\&tid=ACSDT1Y2018.B04006\&hidePreview=false. (Ziyaret Tarihi: 23.08.2020).

Visit Scotland (2020). Ancestral tourism toolkit. https://www.visitscotland.org/supporting-yourbusiness/marketing-toolkits/ancestral-tourism (Ziyaret tarihi: 19.08.2020).

Yessenova, S. (2014). Cinema as branding. İçinde; K. Kantarcı, M. Uysal ve V. Magnini (Edt.) Tourism in Central Asia: Cultural potential and challenges (ss. 173-200) Ontario: Apple Academic Press.

Yücel, M. U. (2014). Samarkand: Queen of all cities. İçinde: Kantarci, K., Uysal, M. ve Magnini, V. (Edt).Tourism in Central Asia: Cultural potential and challenges (ss. 149-173). Toronto: Apple Academic Press.

\section{EXTENDED ABSTRACT}

This study focuses on the recently developing tourism activities, in particular, root tourism, ancestral tourism, and genealogy tourism which help to fulfill the identity and belonging needs of people in the context of culture and heritage. This new tourism type, while providing the sense of nostalgia and sense of belonging by rediscovering the known or unknown past, at the same time seeks answers to questions such 
as who am I and where do I come from in cultural context. Whilst the living conditions of modern era direct people to be more individualistic and egocentric, cultural heritage and belonging oriented tourism types, in a sense represent the connecting with the past and cultural union and reminds the personal and cultural roots. The dimension of this new trend has been investigated in the literature under different concepts such as heritage tourism, root tourism, ancestral tourism, and genealogy tourism. These tourism types, based on cultural heritage, nowadays has been stated as a strategic area for some countries and are used in order to create shared-values, feelings and culture beyond solely being a tourism activity. Hence, the tourism activities bring various disciplines as an academic research area and different units as policy planners and decision-makers for holistic planning.

The primary aim of this study is to conceptualize the new notions developed and used in international literature that arise from new tourism activities such as nostalgia and root tourism in the Turkish language. Besides, through these new tourism activities, contributing to the planning process of the supply and demand conditions that might be developed between Turkey and Central Asia based on common cultural heritage is another important target of the study. Developing the concepts in the national language and wide-spreading their use is of vital importance in terms of understanding the field more easily and deeply and for further development in the relevant field. Thus, the study contributes to related fields and fills an important theoretical gap that could inspire future studies.

The Central Asian region is home to the oldest and most unique tangible and intangible elements of the Turkish history. In this respect, for the Turkish world, the most important supply geography of the heritage-based tourism types, which develops with a focus on cultural context, is the Central Asian Region. Thus, it can be stated that the most competitive tourism field of the region is the root tourism resources. Therefore, creating awareness towards root tourism in the region, including public and private sector and individual base, is of utmost importance in order to manage the process and protect the cultural properties. Determining the resources, the routes and attractions is a very important yet complicated process. Accordingly, developing a root tourism development agenda including all the regional countries is needed.

This study, based on literature review and secondary data, reveals that root tourism is a unique opportunity for the Turks and tourism industries in Turkey and Central Asia, and indicates important contributions that might be both theoretical and managerial. It can be stated that root tourism has also potential to positively impact on the ability of cultural and economic cooperation between Turkey and Central Asian Countries. It might also positively affect the cooperation ability and culture among the region countries, which might lead to create more value-added tourism products for the tourism industry. The development of root tourism in Central Asian Countries, at the same time might pull the cultureoriented tourists worldwide to the region. Hence, the region could be better integrate into the world tourism market and benefit more from its positive impacts of travel and tourism industry. Additionally, this pioneering study is important by means of being an example for examining and supplying to the tourism market of other important areas and cultural heritage elements of the Turkish World.

This study offers new opportunities for tourism development into the Turkish World. The permanent effects of heritage tourism on the perception of culture, assets and identity also necessitate a multidimensional evaluation of this area. Therefore, evaluating the tangible and intangible resources in the area in the context of root tourism might be useful both for the state level as well as the Turkish people all around the world. In this context, developing root tourism activities in Central Asia, beyond being solely a tourism activity, might offer new insights for the Turks in terms of identity, culture, belonging, and sense of nostalgia. Hence, this activity could be referred as a significant tool for creating shared value and reminding the Turks of who we are and where we came from. 